\title{
Comparative electron temperature measurements of Thomson scattering and electron cyclotron emission diagnostics in TCABR plasmas ${ }^{\text {a) }}$
}

\author{
M. P. Alonso, ${ }^{1, b)}$ A. C. A. Figueiredo, ${ }^{1}$ F. O. Borges, ${ }^{2}$ J. I. Elizondo, ${ }^{2}$ R. M. O. Galvão, ${ }^{2}$ \\ J. H. F. Severo, ${ }^{2}$ O. C. Usuriaga, ${ }^{2}$ L. A. Berni, ${ }^{3}$ and M. Machida ${ }^{4}$ \\ ${ }^{1}$ Associação EURATOM/IST, Instituto de Plasmas e Fusão Nuclear-Laboratório Associado, \\ Instituto Superior Técnico, P-1049-001 Lisboa, Portugal \\ ${ }^{2}$ Instituto de Física, Universidade de São Paulo, São Paulo, Brazil \\ ${ }^{3}$ Laboratório Associado de Sensores e Materiais, INPE, São José dos Campos, São Paulo, Brazil \\ ${ }^{4}$ Universidade Estadual de Campinas, Campinas, São Paulo, Brazil
}

(Presented 17 May 2010; received 15 May 2010; accepted 27 August 2010; published online 26 October 2010)

\begin{abstract}
We present the first simultaneous measurements of the Thomson scattering and electron cyclotron emission radiometer diagnostics performed at TCABR tokamak with Alfvén wave heating. The Thomson scattering diagnostic is an upgraded version of the one previously installed at the ISTTOK tokamak, while the electron cyclotron emission radiometer employs a heterodyne sweeping radiometer. For purely Ohmic discharges, the electron temperature measurements from both diagnostics are in good agreement. Additional Alfvén wave heating does not affect the capability of the Thomson scattering diagnostic to measure the instantaneous electron temperature, whereas measurements from the electron cyclotron emission radiometer become underestimates of the actual temperature values. (C) 2010 American Institute of Physics. [doi:10.1063/1.3494379]
\end{abstract}

\section{INTRODUCTION}

The Tokamak Chauffage Alfvén Brésilien (TCABR) main parameters ${ }^{1}$ are the following: major radius of $61.5 \mathrm{~cm}$, minor radius of $18 \mathrm{~cm}$, plasma current of $120 \mathrm{kA}$ with duration $<150 \mathrm{~ms}$, toroidal magnetic field $\leq 1.2 \mathrm{~T}$, peak electron density $\leq 4 \times 10^{19} \mathrm{~m}^{-3}$, and peak electron temperature around $600 \mathrm{eV}$, with solid poloidal divertor rails surrounding the plasma column. The electron temperature is routinely measured using a sweeping heterodyne radiometer ${ }^{2}$ (SHR) and a recently installed Thomson scattering diagnostic (TSD). ${ }^{3}$ Both diagnostics employ the conventional technologies that have been in use in other tokamaks. Taking into consideration the instantaneous and local electron temperature values provided by the TSD and the average value from the SHR, a good agreement is generally obtained between the measurements of the two diagnostics. The anticipated exception to this agreement occurs in discharges for which plasma densities are close to the electron cyclotron emission (ECE) cutoff. ${ }^{4}$

\section{MEASUREMENT USING THE ELECTRON CYCLOTRON EMISSION RADIOMETER}

A diagnostic for measuring electron cyclotron emission (ECE) using a microwave detection system is in routine operation at the TCABR tokamak. This system is based on a sweeping heterodyne radiometer (SHR) that operates in the frequency band of $52-85 \mathrm{GHz}$. It can operate in fixed fre-

\footnotetext{
a) Contributed paper published as part of the Proceedings of the 18th Topical Conference on High-Temperature Plasma Diagnostics, Wildwood, New Jersey, May, 2010.

b)Electronic mail: alonso@ipfn.utl.pt.
}

quency mode with a maximum resolution of $10 \mu$ s and in sweeping mode with $50 \mu$ s per frequency step. ${ }^{2}$ The receiver system has a Gaussian antenna for improved space resolution down to $2 \mathrm{~cm}$. The antenna axis lies on the toroidal equatorial plane of the machine, perpendicularly to the plasma column. The radiometer is located $5 \mathrm{~m}$ away from the tokamak. This arrangement allows ECE detection in $\frac{3}{4}$ of the plasma column. A block diagram of the radiometer is shown in Fig. 1.

It has been clearly established that for a toroidal magnetic field higher than $1.14 \mathrm{~T}$, the plasma electron density is high enough for some frequencies of the electron cyclotron emission to be cut off in the TCABR plasma core ( $\mathrm{r}$ $<5 \mathrm{~cm}){ }^{2}$ Indeed, when the local density is higher than $2.3 \times 10^{19} \mathrm{~m}^{-3}$, the electron temperature cannot be measured by the SHR (X-mode second harmonic). There is no such density limitation for the TSD.

The time evolution of some relevant TCABR plasma parameters is shown in Fig. 2 for shot No. 24508. A 7 ms pulse of radio-frequency (rf) power has been applied to the plasma starting at $\mathrm{t}=70 \mathrm{~ms}$, during the quasistationary phase of the plasma current. ${ }^{5}$ Although the antenna straps are protected by boron nitride (BN) lateral plates, the rf power still causes desorption at their metal surface, which leads to an increase of the plasma density. Consequently, as the average electron density-depicted in the first graph of Fig. 2-surpasses $1.5 \times 10^{19} \mathrm{~m}^{-3}$, the ECE cutoff is crossed, which is manifested in the rapid fall of the ECE signal shown in the second graph of Fig. 2. Edge cooling by desorption degrades confinement right after the end of the rf pulse, with increased outward energy transport. The consequent narrowing of the current channel triggers magnetohydrodynamics 


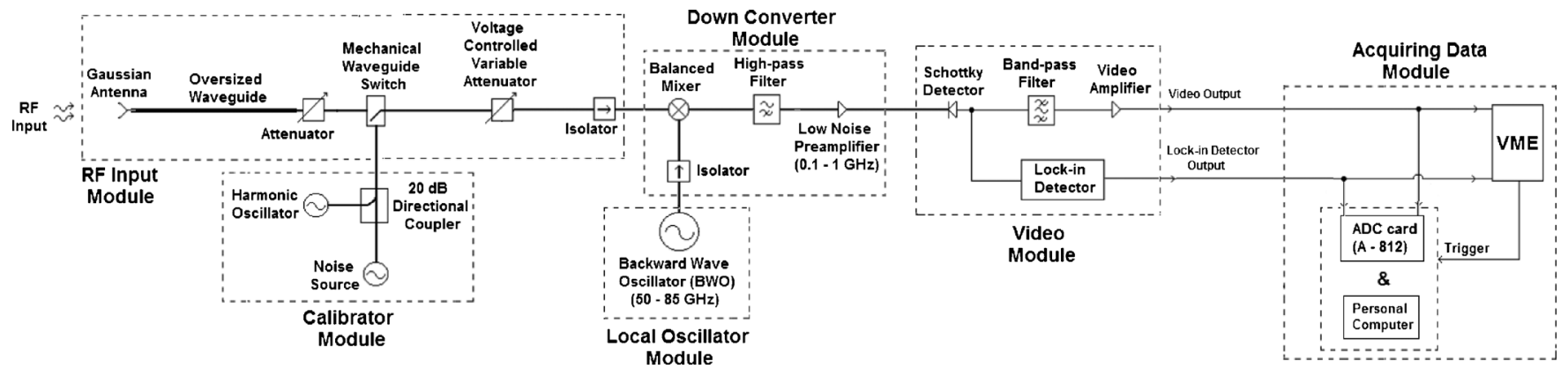

FIG. 1. Scheme of the ECE radiometer at TCABR tokamak.

instabilities that are clearly visible in the Mirnov coil- third graph in Fig. 2. The plasma current drops slowly by approximately $10 \%$, which indicates effective electron heating despite the increased average electron density. ${ }^{6}$

\section{TEMPERATURE MEASUREMENT USING THE THOMSON SCATTERING DIAGNOSTIC}

An incoherent and infrared TSD has been assembled on the TCABR tokamak, ${ }^{3}$ making use of some components previously installed at the Instituto Superior Técnico Tokamak (ISTTOK). ${ }^{7}$ The TSD uses a neodymium:glass laser with up to $10 \mathrm{~J}$ per laser pulse and a first generation polychromator with three pairs of interference filters and avalanche photodiodes (Fig. 3). It measures $90^{\circ}$ scattered radiation in a single volume of observation $(\mathrm{r}=0$, the observation volume has $18 \mathrm{~mm}$ length and $2 \mathrm{~mm}$ diameter), with a single $40 \mathrm{~ns}$ laser pulse to obtain the instantaneous plasma electron temperature. To commission the TSD, it was necessary to develop a new performance model, ${ }^{8}$ to refurbish the laser, to install a new laser delivery system and a new collecting lens, to properly take care of stray-light reduction, and to perform the calibration for temperature measurement. ${ }^{9}$ A long run of experiments with this diagnostic shows consistency and coherence with the physics program of the TCABR tokamak. In

\section{TCAgS SHOT\# 24508}
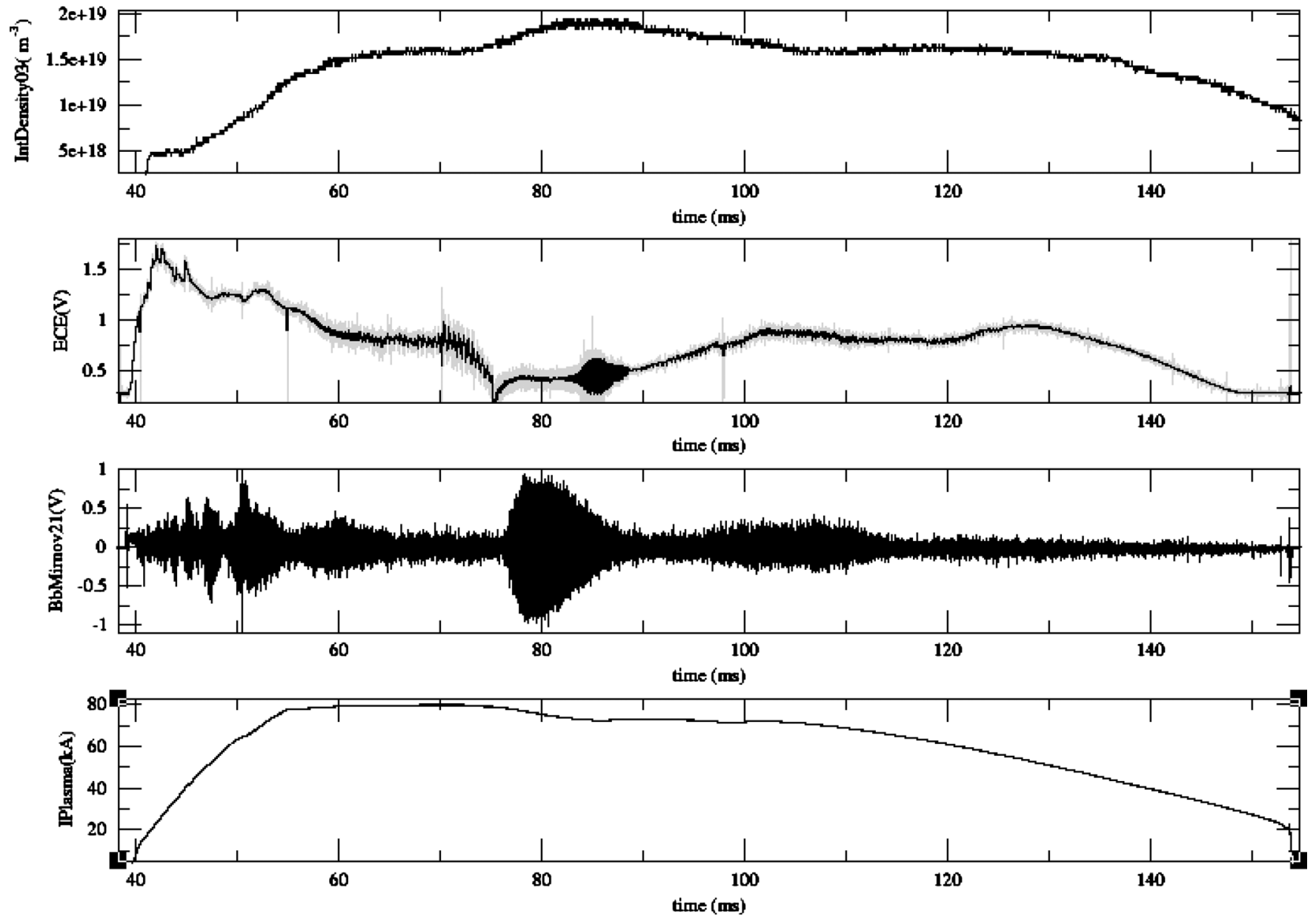

FIG. 2. Line integrated electron density, ECE signal, Mirnov coil signal, and toroidal plasma current for TCABR shot No. 24508. Alfvén heating is applied from 70 to $77 \mathrm{~ms}$. 


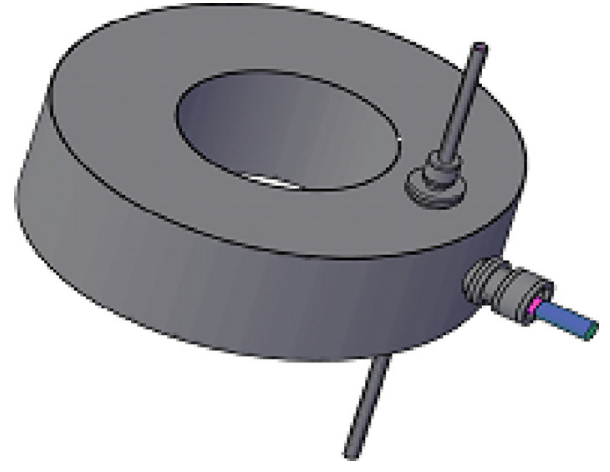

FIG. 3. (Color online) Outside view of the Thomson scattering section in the TCABR vacuum chamber showing the two vertical laser input and output pipes and the horizontal glass window with the horizontal collecting lenses.

Fig. 4 we have the electron temperature raw data from the TSD at $\mathrm{t}=73.6 \mathrm{~ms}$, when a peak electron density of 2.3 $\times 10^{19} \mathrm{~m}^{-3}$ is expected, according to the above discussion of Fig. 2.

The TSD measured signal-to-noise ratio $(\mathrm{S} / \mathrm{N})$ is around 5 at the plasma radius $\mathrm{r}=0$ with a $5 \mathrm{~J}$ laser pulse and neglectable stray-light (see Fig. 4). By considering a parabolic radial density profile and a linear dependence of the TSD signal on electron density, we can anticipate an $\mathrm{S} / \mathrm{N}$ of 1 at the plasma edge $(r=15 \mathrm{~cm})$, which inhibits the edge electron temperature measurements.

\section{TCABR ALFVÉN WAVE HEATING PROGRAM}

Alfvén waves (AWs) are regularly lunched into the TCABR tokamak for local and global plasma heating ${ }^{5,10}$ and for plasma diagnostic. ${ }^{11} \mathrm{AW}$ heating is based on mode conversion of an externally driven rf field into kinetic or electrostatic Alfvén waves at the localized Alfvén resonance layer. Evidence of AW resonant heating has been found at TCABR, thus confirming core heating. ${ }^{6,12}$ The AWs are also used to find the effective ion mass number and the radial profile of the safety factor in tokamak plasmas. ${ }^{13}$ In the basic regime of operation at TCABR, the AWs are excited by two antenna modules. For plasma shot No. 24508 the rf power delivered by the antenna was less than $40 \mathrm{~kW}$ and the fre-

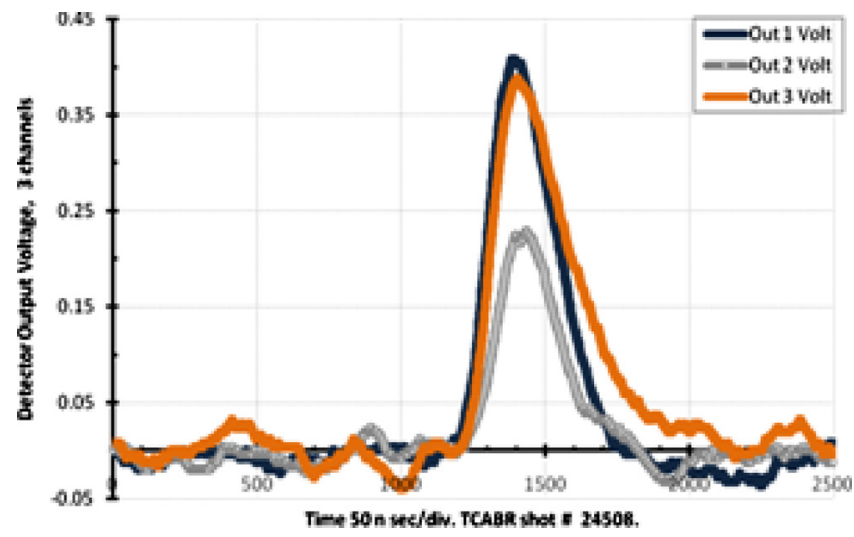

FIG. 4. (Color online) Thomson scattering raw signals for TCABR shot No. 24508, yielding an instantaneous local electron temperature of $491 \mathrm{eV}$ at $\mathrm{r}$ $=0$ (laser firing at $73.6 \mathrm{~ms}$ ).

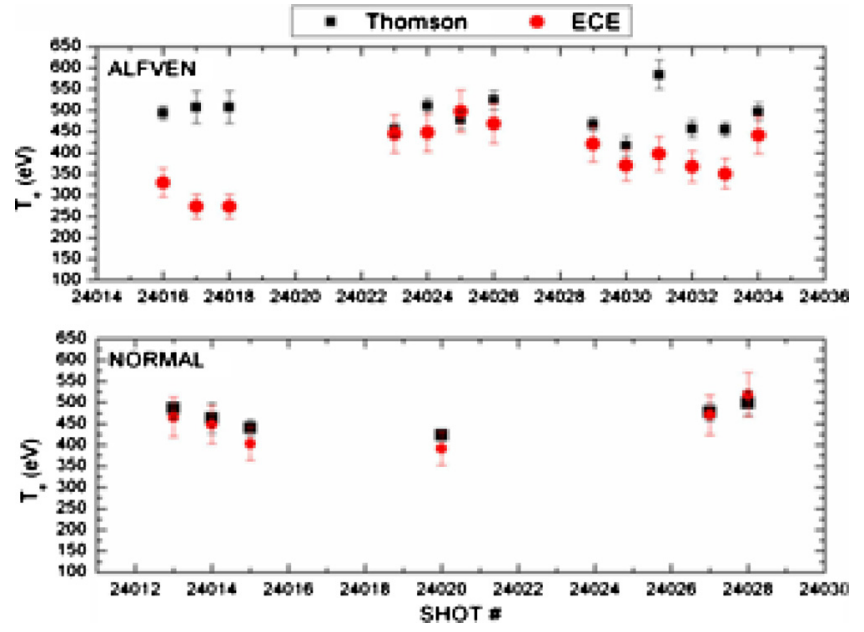

FIG. 5. (Color online) A series of electron temperature measurements for TCABR plasma shot Nos. from 24012 to 24034. The electron temperature obtained by the ECE (in solid gray circles) compared with the values from the TSD (in black squares) at the same time instant. Showing (top graph) a clear disagreement between TSD and ECE when Alfvén wave heating is applied at high plasma density and (bottom graph) a good agreement for purely Ohmic discharges.

quency was fixed at $5.0 \mathrm{MHz}$. Different theoretical models ${ }^{5,14}$ agree in that the radial distribution of the power absorbed by the plasma is strongly localized around $r=2,10$, and $16 \mathrm{~cm}$, with a spatial resolution around $4 \mathrm{~cm}$. Currently, these resonances cannot be detected by the TSD diagnostic, since there is a single observation volume.

\section{SIMULTANEOUS ECE AND TSD MEASUREMENTS}

Previous to the commissioning of the Thomson scattering diagnostic, the microwave radiometer system described in Sec. II was already in operation at TCABR for electron cyclotron emission measurements. The radiometer is regularly used to obtain the time evolution and radial profiles of the electron temperature in purely Ohmic plasmas. The full year of 2009, including an intensive, successful experimental campaign of two weeks has been dedicated to ensure that the TSD diagnostic was able to perform regularly without any need for changes in the diagnostic parameters or in the optical alignments. At the same time, we compared TSD electron temperature measurements with ECE measurements. During this period we measured electron temperatures from 50 up to $600 \mathrm{eV}$ with an excellent agreement with ECE measurements in Ohmic discharges and with a strong toroidal magnetic field $(1.14 \mathrm{~T})$ and line averaged density lower than 1.5 $\times 10^{19} \mathrm{~m}^{-3}$. With additional Alfvén wave heating and for high density plasmas (line averaged density bigger than 1.5 $\times 10^{19} \mathrm{~m}^{-3}$ ), the ECE diagnostic was unable to perform adequately (as shown in the top graph of Fig. 5) measuring systematically lower values for the electron temperatures than the Thomson scattering diagnostic.

\section{CONCLUSIONS}

In particular conditions the newly installed Thomson scattering diagnostic was able to measure the electron temperature at the tokamak TCABR using a single laser pulse 
and a single detector. These TSD measurements are in quite satisfactory agreement with the sweeping heterodyne radiometer measurements for Ohmic discharges. For plasma discharges with Alfvén heating, the ECE diagnostic does not provide correct results due to the increased peak plasma density. On the other hand, there is an improvement in the signal to noise ratio of the TSD as the plasma density increases. In the measurements reported here, $\mathrm{S} / \mathrm{N}$ amounts to a factor of 5 measured in the plasma center and a calculated value of 1 at the plasma edge, which is unsatisfactory. Therefore, for the benefit of the TCABR physics program, there is a plan to upgrade the TSD to (i) accommodate a laser pulse energy up to five times larger to increase the efficiency of the scattered photon to electron conversion and be able to measure at the plasma edge; (ii) increase the number of observation volumes, at least to 3, to measure the localized Alfvén resonant layer; and (iii) to increase the number of laser pulses fired during the $7 \mathrm{~ms}$ of Alfvén heating.

\section{ACKNOWLEDGMENTS}

The authors wish to thank the "Fundação de Amparo à Pesquisa do Estado de São Paulo" FAPESP, for one fellowship and general support, "Conselho Nacional de Pesquisa e Desenvolvimento" CNPq (Brazil), E. Kenzo Sanada for the diagnostics control, and Leonid Ruchko (TCABR) for the Alfvén heating details. This work has been conducted under the European Fusion Development Agreement (EFDA), as well as within the framework of the Contract of Association between the European Atomic Energy Community and the "Instituto Superior Técnico" IST (Portugal). The content of this publication is the sole responsibility of the authors and does not necessarily represent the views of the European Commission or their services.
${ }^{1}$ V. Bellintani, Jr., A. G. Elfimov, J. I. Elizondo, A. N. Fagundes, A. M. M. Fonseca, R. M. O. Galvão, L. Guidolin, Yu. K. Kuznetsov, E. A. Lerche, M. Machida et al., AIP Conf. Proc. 875, 350 (2006).

${ }^{2}$ R. P. Silva, A. M. M. Fonseca, J. H. Vuolo, E. R. Calderon, R. M. O. Galvao, Y. K. Kuznetzov, and J. C. Raffaelli, Braz. J. Phys. 34, 1771 (2004).

${ }^{3}$ M. P. Alonso, L. Berni, J. H. Severo, F. O. Borges, J. I. Elizondo, M. Machida, C. A. F. Varandas, and R. M. O. Galvao, AIP Conf. Proc. 996, 192 (2008).

${ }^{4}$ A. M. M. Fonseca, R. P. Silva, R. M. O. Galvao, Y. K. Kuznetzov, J. I. Elizondo, E. R. Calderon, L. F. Ruchko, and J. H. Vuolo, Braz. J. Phys. 34, 1780 (2004).

${ }^{5}$ A. G. Elfimov, E. A. Lerche, R. M. O. Galvao, L. F. Ruchko, A. M. M. Fonseca, R. P. Silva, and V. Bellintani, Braz. J. Phys. 34, 1707 (2004).

${ }^{6}$ C. Ribeiro, V. Bellintani, A. G. Elfimov, J. I. Elizondo, A. N. Fagundes, R. M. O. Galvao, Y. K. Kuznetsov, I. C. Nascimento, E. M. Ozono, L. F. Ruchko et al., AIP Conf. Proc. 875, 377 (2006).

${ }^{7}$ M. P. Alonso, P. D. Wilcock, and C. A. F. Varandas, Rev. Sci. Instrum. 70, 783 (1999).

${ }^{8}$ M. P. Alonso, A. C. A. Figueiredo, L. A. Berni, and C. A. F. Varandas, IEEE Trans. Plasma Sci. 36, 1094 (2008).

${ }^{9}$ C. A. F. Varandas, C. Silva, V. A. Gribkov, A. Malaquias, and G. V. Oost, Nucl. Fusion 48, 077001 (2008).

${ }^{10}$ R. Galvão, V. Bellintani, R. Bengtson, A. Elfimov, J. Elizondo, A. Fagundes, A. Ferreira, A. Fonseca, Y. Kuznetsov, E. Lerche, C. Nascimento, L. F. Ruchko, W. P. de Sá, E. A. Saettone, E. Sanada, J. H. F. Severo, R. P. da Silva, V. S. Tsypin, O. C. Usuriaga, and A. Vannucciand, Plasma Phys. Controlled Fusion 43, 299 (2001).

${ }^{11}$ A. G. Elfimov, L. F. Ruchko, R. M. O. Galvao, J. I. Elizondo, E. Sanada, Y. K. Kuznetsov, A. N. Fagundes, W. P. De Sa, C. A. F. Varandas, M. E. C. Manso, P. Varela, A. Silva, and A.A. Ivanov, Nucl. Fusion 46, S722 (2006).

${ }^{12}$ R. M. O. Galvao, V. Bellintani, Jr., A. G. Elfimov, A. N. Fagundes, A. M. M. Fonseca, Yu. K. Kuznetsov, E. A. Lerche, I. C. Nascimento, E. K. Ozono, L. F. Ruchko, J. H. F. Severo, R. P. da Silva, O. C. Usuriaga, and A. Vannucci, 30th EPS Conference on Controlled Fusion and Plasma Physics, 2003, ECA Vol. 27A, O-4.2B.

${ }^{13}$ L. F. Ruchko, R. Valencia, R. M. O. Galvao, E. A. Lerche, A. G. Elfimov, V. Bellintani, Jr., J. I. Elizondo, A. N. Fagundes, A. M. M. Fonseca, Y. K. Kuznetsov, I. C. Nascimento, W. P. de Sá, E. Sanada, and R. P. da Silva, Rev. Sci. Instrum. 75, 655 (2004).

${ }^{14}$ E. H. Lyvio and P. R. S. Rosa, Braz. J. Phys. 34, 1602 (2004). 